\title{
Study on the weight coefficient influence of surface water on the stability of open-pit dump. Comparative analysis of 6 degree seismic simulation
}

\author{
Zhen-guo Xing ${ }^{1}$, Wenfeng $\mathrm{Du}^{2}$ \\ State Key Laboratory of Coal Resources and Safe Mining, \\ China University of Mining and Technology (Beijing), Beijing, China \\ College of Geoscience and Surveying Engineering, China University of Mining and Technology (Beijing), \\ Beijing, China \\ ${ }^{2}$ Corresponding author \\ E-mail: ${ }^{1}$ xing-919@qq.com, ${ }^{2}$ duwf66@126.com
}

Received 23 April 2017; accepted 24 April 2017

DOI https://doi.org/10.21595/vp.2017.18535

\begin{abstract}
Taking Baorixile open-pit coal mine as an example, the regional hydrogeological conditions and the mining area hydrogeological conditions are briefly introduced. Analyzing the factors influencing the stability of open pit dump, discussing the classification and proportion of influencing factors, the numerical simulation of the influence of surface water and seismic vibrations on the stability of open-pit dump is carried out. Results show: Surface water is an important factor affecting the stability of open-pit dump, extremely sensitive to the safety factor, the influence of slope instability is similar to that of intensity 6 earthquake. The weight coefficient of surface water to slope stability is in the range of 0.4 to 0.9 .
\end{abstract}

Keywords: open-pit coal mine dump, surface water, weight coefficient, numerical simulation.

\section{Introduction}

The effects of atmospheric precipitation and surface water on the stability of open-pit are very large. Rainfall infiltration increases the water content of the unsaturated zone of the slope, matrix suction decreases, the shear strength of the unsaturated soil in the slope soil is reduced, the soil water pressure increases and the strength decreases, dump stability is affected. Serious geological disasters occurred in China during the period of 7-9 months of flood season, this shows that most of the geological disasters are closely related to atmospheric rainfall. From here we see that the effect of water on slope stability is very large, sometimes even disastrous. In the process of slope treatment, surface water and ground water from rainfall must be highly valued by engineers [1-8].

The stability of the dumping site affects the size of the land, the choice of the soil drainage scheme and parameters, and the determination of the reasonable drainage technology. The instability of the dump can affect the normal production and the safety of the personnel equipment in the open stope and dump. It is very difficult to predict slope stability accurately, because of the geological conditions, rock mass mechanical properties, environmental factors and so on, it has the characteristics of uncertainty and fuzziness. In this paper, combine with the actual situation and historical data of Baorixile open-pit mine dump, analysis the weight coefficient of the influence of surface water on the stability of dump. In order to more intuitively explain the impact of rainfall on slope stability, the safety factor of the dump will be compared under the condition of 6 degree seismic intensity, because seismic damage is a natural disaster that can't be predicted by human beings which is a representative event.

\section{General situation of study area}

Baorixile open-pit coal mine is located in the north of the Hailar river, its macro topography shows a slight fluctuation of the high plain, southwest low. In this area, 6-8 month is rainfall concentrated period. From 2004 to 2006, began to carry out the initial experimental inner row; At present, the basic realization of all internal row. The base of the inner dumping site is a deep gray 
mudstone, sandstone and thin coal seam with good cementation of coal seam floor, the occurrence of basement and lithology are very unfavorable to the stability of the dumping site. In addition, the seepage and seepage of coal seam confined water, making basement mudstone soft, shear strength reduction, the stability of the inner dump is worse. November 2005, May 2006, occurred within 2 times the phenomenon of internal dumping instability. The regional hydrogeological map of Baorixile open-pit mine see Fig. 1.

Since April 28, 2009, there was obvious settlement with the increase of soil strength in the dump. In May 2nd, the $+660 \mathrm{~m}$ settlement of the dump was intensified and the displacement was obvious, landslide in the dump about 2 hours. The landslide area is about $750 \mathrm{~m}$ in the north south direction, $630 \mathrm{~m}$ in east-west direction, the landslide area is about 450 thousand $\mathrm{m}^{2}$. After the landslide occurred, the soil drainage step was recovered from both sides of the inner dumping site, the front of the sliding body moved south nearly $100 \mathrm{~m}$ in end of 20096 .

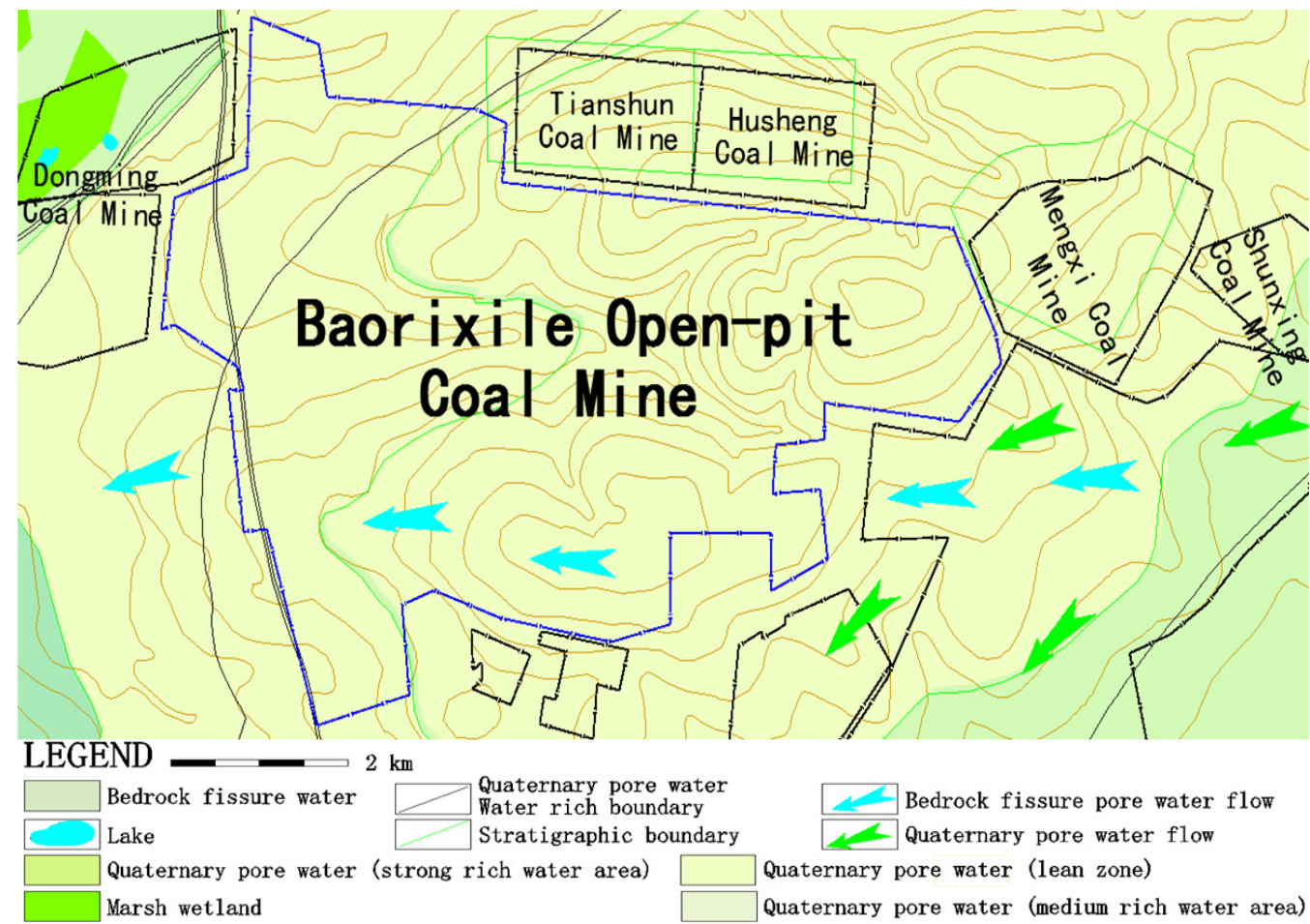

Fig. 1. Regional hydrogeological map of Baorixile open-pit mine

\section{Factors affecting stability of dump}

a) Conditions of geography and geological. It includes the topography of the dumping ground, the characteristics of the surface water, the precipitation of the atmosphere, the freezing and thawing of the slope. The freezing surface of a certain area dump in winter in cold area, frozen soil can be formed in the dump when the water is supplied, to form a weak surface after thawing.

b) Mining engineering activities. There are many mining factors influencing the stability of waste dump, the main is mining program and the dumping sequence. It includes the degree of fragmentation of the abandoned rock, the method of soil drainage, the width of the strip and the advancing speed of the drainage line.

Blasting vibration is also a crucial cause. The daily blasting of open pit mines and the borders blasting have affected slope stability.

c) Properties of dump. The composition of the mixture is different in size, composition, 
structure, water content and so on, because of the mining process, the dumping site, the role of water, etc. Its physical and mechanical properties and the original soil and rock ratio, it is very complex.

The volume of undisturbed soil is increased after blasting, mining and discharging, and because of its own weight and the role of soil and another mechanical load gradually tightening. There is no cohesive force in hard and non-cohesive rock, the shear strength index can be expressed by the internal friction coefficient and the tangent of the natural slope angle. The natural slope angle of some rock dump see Table 1.

Table 1. Natural slope angle of some rock dump

\begin{tabular}{|c|c|c|c|}
\hline \multicolumn{2}{|c|}{ Rock characteristics of dump } & Height of dump (m) & Natural slope angle $\left(^{\circ}\right)$ \\
\hline \multirow{2}{*}{ Coal bearing rock } & Outer dump & $9-11$ & $32-26$ \\
\cline { 2 - 4 } & Inner dump & $20-30$ & $34-37$ \\
\hline \multicolumn{2}{|c|}{ Waste dump } & $30-50$ & $34-37$ \\
\hline \multicolumn{2}{|c|}{ Limestone and shale } & $<50$ & $33-35$ \\
\hline \multicolumn{2}{|c|}{ Syenite and porphyrite } & $<30$ & $32-35$ \\
\hline \multicolumn{2}{|c|}{ Metamorphic rock } & - & 37.6 \\
\hline
\end{tabular}

\section{Factor classification and weight coefficient analysis}

\subsection{Factor classification}

There are many factors that affect the stability of the dump slope, summed up mainly in the following areas:

a) Regional geological conditions of dump;

b) Physical and mechanical properties of slope material;

c) Slope shape and size;

d) Slope working conditions, such as load;

e) The role of water.

Water is one of the important factors of slope instability. According to statistics, $90 \%$ of China's slope instability is related to surface water and groundwater activities. There are a lot of landslides, collapse, debris flow and other slope instability phenomenon after the rainstorm, this is enough to show that water is an important factor affecting slope deformation and stability.

\subsection{Numerical simulation verification}

Selecting the longest distance from the dump as the center section, the landslide slope as the boundary section. The distribution of pore water pressure in unsaturated soil slope under rainfall infiltration was calculated by SEEP/W software, the safety factor is calculated from the calculation result. The water level lines and head distributions of the transient seepage field under the conditions of continuous heavy rainfall and short rainstorm were simulated. The model of slope profile before and after rainfall see Fig. 2.

The safety factor of the dump boundary is 1.185 when the rainfall is not considered, in the rainfall infiltration down to 1.08 , after continuous rainfall fell to 1.063 . The safety factor of the dump centery is 1.218 when the rainfall is not considered, in the rainfall infiltration down to 0.90 , after continuous rainfall fell to 0.807 . Also check the boundary section of the weak surface but after the artificial reinforcement of the situation. In the presence of groundwater, no rainfall infiltration of the safety factor of 1.30, the groundwater level rises after rainfall infiltration, the moisture content in the weak surface increases, safety factor down to 0.9 , prone to landslides at this time. The relationship between safety factor and rainfall in slope of dump see Fig. 3 . 

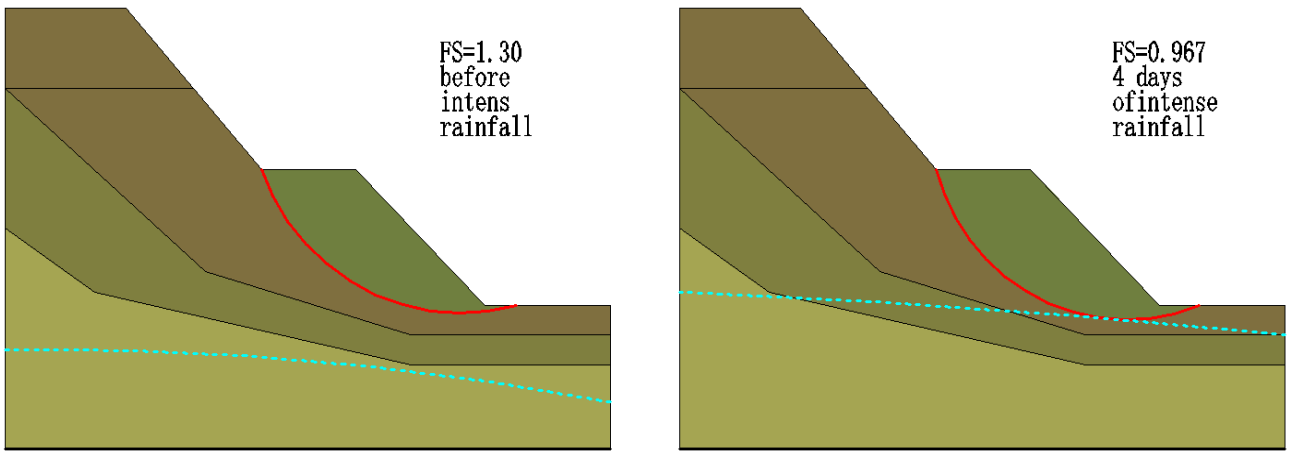

Fig. 2. FS of slope over rainfall event

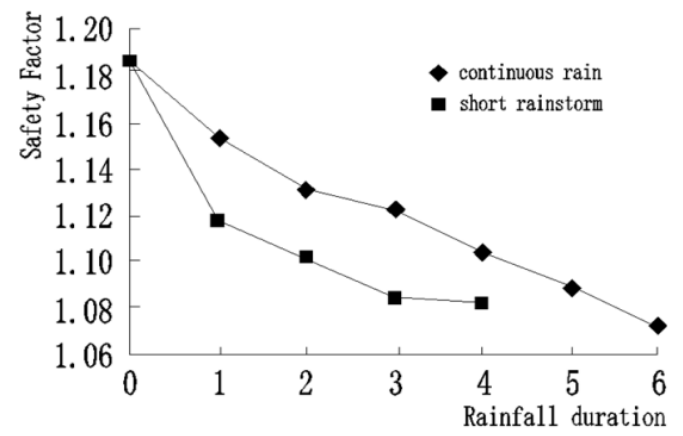

a) Boundary section

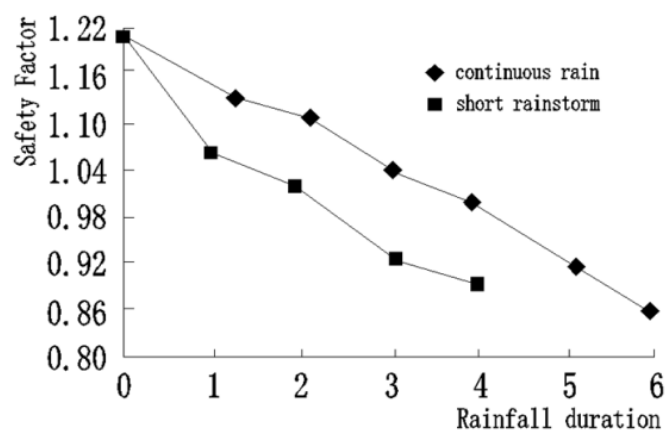

b) Center section

Fig. 3. Relationship between safety factor and rainfall in slope of dump

\subsection{Analysis of surface water weight coefficient}

From the classification, there are two main factors influencing the occurrence of geological disasters, geological background factors and a variety of man-made or natural external dynamic factors. Statistics of the causes of landslide accidents in previous dumps, rain caused 37 landslides, accounting for $90 \%$ of all landslide accidents.

The effect of surface water on soil slope is mainly manifested in erosion, which includes surface erosion and groove erosion. In the role of rain, the water flow in the slope of the process of more uniform erosion of the entire slope of the loose material so that the slope decreased, the slope after the shift so that the formation of surface erosion. Gully erosion is the flow of water in the slope of the process, due to the uneven surface of the slope, there is a certain groove and low concave, when the water more than a low concave or trench water storage capacity began to form a linear flow. Surface water infiltration into the slope, not only increased the weight of the overlying soil, resulting in the slope of the sliding force increases, and seepage on the sliding belt soil wetting and lubrication, making the sliding soil moisture content increased pore water pressure. The effective strength is reduced, which will lead to greatly reduce the resistance of the sliding, thus affecting the stability of the slope.

When the groundwater comes into contact with the rock crevice, the water produces hydrostatic pressure on both walls of the fissure. Fracture water static pressure is one of the important static loads produced by groundwater to slope rock mass. Fracture water static pressure of the direction of action perpendicular to the pressure surface, this force can reduce the anti-slip force of about $20 \%$ to $40 \%$ in some cases. The schematic diagram of the ilnternal partition of open-pit mine dump see Fig. 4.

According to the results of numerical simulation analysis can be analyzed in other factors to the same circumstances, surface water (rainfall) affect the safety factor of the dump below the 
safety threshold in the slope center, the minimum safety factor is $71.8 \%$ and $73.89 \%$ respectively. Surface water (rainfall) to greatly reduce the safety factor of the dump, approaching safety thresholds are in the dump boundary, the minimum safety factor is $89.7 \%$ and $91.11 \%$, respectively. The slope center does not fall as a result of boundary displacement constraints, so it is only a reference to the boundary safety factor. Dump boundary in the rainfall infiltration 6 hours after the safety factor close to 1 , indicating the risk of a landslide to occur. This is consistent with $90 \%$ of the actual results of the landslide caused by rainfall, indicating that the numerical simulation results are reliable.

Based on the above statistics and calculations, the conditions of geography and geological, mining engineering activities and properties of dump of the maximum weight coefficient is about $20 \%$. So, the minimum weight coefficient of surface water is about $40 \%$, the maximum value is $90 \%$. The weight coefficient of surface water to slope stability is in the range of 0.4 to 0.9 .

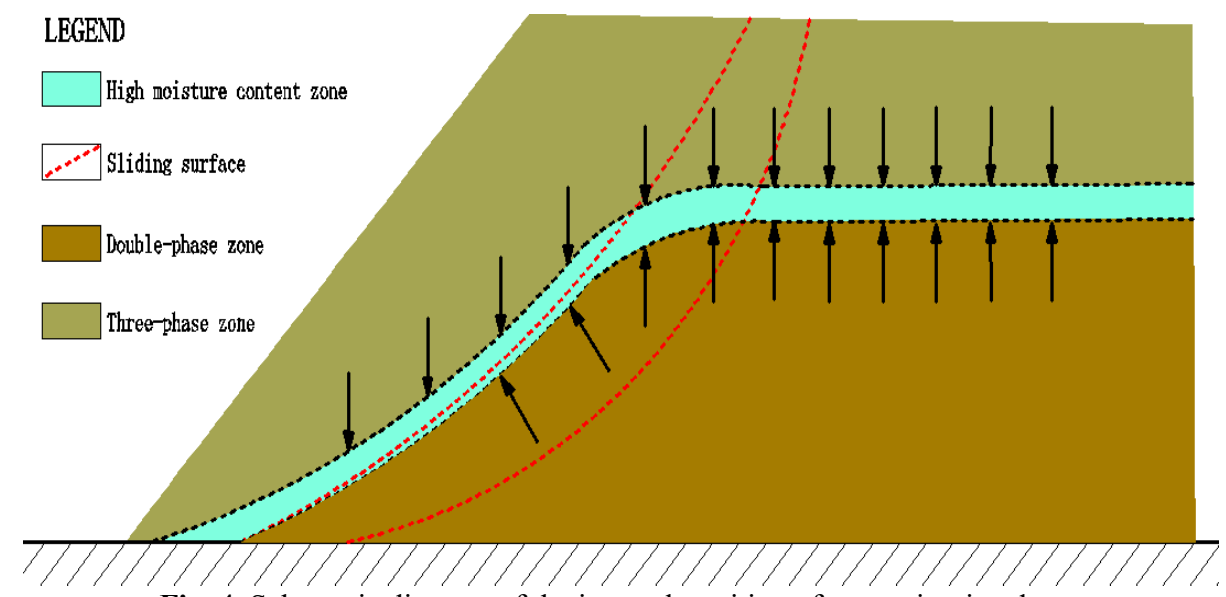

Fig. 4. Schematic diagram of the internal partition of open-pit mine dump

\section{Conclusions}

1) Analyzing the factors influencing the stability of open pit dump, such as conditions of geography and geological, mining engineering activities and properties of dump.

2) Discussing the classification and proportion of influencing factors, the numerical simulation of the influence of surface water on the stability of open-pit dump is carried out. Results show: The minimum weight coefficient of surface water is about $40 \%$, the maximum value is $90 \%$. The weight coefficient of surface water to slope stability is in the range of 0.4 to 0.9 .

3) The influence of continuous rainfall on slope stability is similar to that of 6 degree seismic intensity: there is no landslide risk, but the safety factor is small.

4) Only an open-pit mine dumping was verified and verified, but the mine is located in the rainy season concentrated areas, groundwater is more developed, the conclusion is only applicable to such conditions of opencast mines, other cases of open pit mine still need further analysis.

\section{Acknowledgements}

Financial supports from the State Key Research Development Program of China (2016YFC0501102) is greatly appreciated.

\section{References}

[1] Surinaidu L. Hydrogeological and groundwater modeling studies to estimate the groundwater inflows into the coal Mines at different mine development stages using MODFLOW, Andhra Pradesh, India. Water Resources and Industries, Vol. 7, Issue 8, 2014, p. 49-65. 
[2] Huang Ming, Peng Suping, Zhang Lijuan, et al. Design and implementation of an environmental monitoring system based on GIS, SMS/GPRS. Journal of Harbin Engineering University, Vol. 29, Issue 7, 2008, p. 749-754.

[3] Jakóbczyk Joanna, Cała Marek, Stopkowicz Agnieszka What were the reasons for the rapid landslide occurrence in "PIASECZNO" open pit? Analysis the landslide process. Studia Geotechnica et Mechanica, Vol. 37, Issue 2, 2015, p. 25-35.

[4] Huang Tao, Luo Xiyuan, Wu Qiang, et al. Model testing study on slope stability under environment of surface water permeation. Chinese Journal of Rock Mechanics and Engineering, Vol. 23, Issue 16, 2004, p. 2671-2675.

[5] Hawkins R. D. Sensitivity of sandstone strength and deformability to changes in moisture content. Quarterly Journal of Engineering Geology, Vol. 25, 1992, p. 115-130.

[6] Xu Jialin, Zhu Weibin, Lai Wenqi, et al. Greenmining techniques in the coalmines of China. Journal of Mines, Metals and Fuels, Vol. 52, Issue 12, 2004, p. 395-398.

[7] Black A., Trumm D., Lindsay P. Impacts of coal mining on water quality and metal mobilisation: case studies from West Coast and Otago. Metal Contaminants in New Zealand, Vol. 12, Issue 4, 2005, p. 247-260.

[8] Qian Minggao On sustainable coal mining in China. Journal of China Coal Society, Vol. 35, Issue 4, 2010, p. 529-534. 